\title{
PERENCANAAN SALURAN PRIMER SUNGAI JAWI DENGAN KEMAM PUAN SWA PURIFIKASI SALURAN TERHADAP BEBAN PENCEMAR ORGANIK
}

\author{
Grisofy Pangaribuan ${ }^{1}$, Winardi Yusuf ${ }^{2}$, Kiki Prio Utomo ${ }^{3}$ \\ Program Studi Teknik Lingkungan, Universitas Tanjungpura, Pontianak \\ grisofypangaribuan@yahoo.com
}

\begin{abstract}
ABSTRAK
Hasil pemantauan kualitas air Sungai Jawi oleh BLH Kota Pontianak tahun 2011 khususnya BOD berdasarkan PP No. 82 Tahun 2001 tentang Pengelolaan Kualitas Air dan Pengendalian Pencemaran Air untuk perairan kelas II telah melebihi baku mutu, mencapai rata-rata $13,7 \mathrm{mg} / \mathrm{l}$. Hal ini menandakan adanya bahan organik yang masuk ke Sungai Jawi sehingga mengakibatkan penurunan kualitas air akibat berkurangnya kemampuan swa purifikasi. Maka dari itu, dilakukan upaya untuk meningkatkan kemampuan swa purifikasi Sungai Jawi agar kualitas air tetap terjaga. Upaya untuk meningkatkan kemampuan swa purifikasi diawali dengan melakukan uji kualitas air khususnya parameter DO sebagai data pembanding hasil perencanaan. Hasil uji laboratorium diketahui konsentrasi DO Sungai Jawi rata-rata 2,2 mg/l ketika pasang dan 1,7 mg/l ketika surut. Kemudian ditetapkan DO target sesuai PP. No 82 Tahun 2001 tentang Pengelolaan Kualitas Air dan Pengendalian Pencemaran Air untuk perairan kelas II sebesar $4 \mathrm{mg} / \mathrm{l}$. Setelah itu dipilih cara untuk meningkatkan laju penambahan Oksigen $(\mathrm{Kr})$ yaitu dengan merubah dinding saluran menjadi beton atau susunan batu atau penambahan alat. Penambahan aerator menjadi cara yang dipilih untuk meningkatkan DO Sungai Jawi. Aerator yang diaplikasikan merupakan aerator permukaan yang diletakkan per 200 meter di sepanjang Sungai Jawi sebanyak 30 buah dengan level daya berkisar antara 18,73-180,37 W/m³.
\end{abstract}

Kata kunci: Sungai Jawi Pontianak, swa purifikasi, aerator

\begin{abstract}
The result of water quality monitoring in Sungai Jawi by BLH Pontianak in 2011 showed that BOD value have exceeded the maximum value according to PP No. 82 th 2001 on Water Quality Management and Water Pollution Control for Class II, reaching an average of $13,7 \mathrm{mg} / \mathrm{l}$. This indicates the presence of organic matter into the Sungai Jawi resulting in deterioration of water quality due to reduced ability of self-purification. Therefore, efforts to improve the ability of self-purification in order Sungai Jawi water quality is maintained. Efforts to increase the ability of self-purification begins to test water quality parameters of DO in particular as the result of planning comparative data. Laboratory test results are known DO concentration Sungai Jawi average of $2,2 \mathrm{mg} / \mathrm{l}$ when the tide and $1.7 \mathrm{mg} / \mathrm{I}$ when it receded. DO then targets set in PP. No. 82 of 2001 on Water Quality Management and Water Pollution Control for Class II waters by $4 \mathrm{mg} / \mathrm{l}$. After the chosen way to increase the rate of addition of oxygen $(\mathrm{Kr})$ is to change the channel wall into concrete or stone structure or addition of equipment. The addition of aerators becoming the preferred method for improving DO Sungai Jawi. Aerator used are surface aerator applied is laid per 200 meters along the river Jawi as many as 30 pieces with power levels ranging from 18,73 to $180,37 \mathrm{w} / \mathrm{m}^{3}$.
\end{abstract}

Keyword: Sungai Jawi Pontianak, self purification, aerator

\section{PENDAHULUAN}

Sungai Jawi merupakan salah satu saluran primer yang ada di Kota Pontianak. Aliran Sungai Jawi berada di Kecamatan Pontianak Barat, Kota Pontianak. Sungai ini mempunyai panjang 6,17 km, dengan lebar antara 12 - 17 meter, dan kedalaman aliran antara 1- 2 meter. Sungai Jawi berfungsi tidak hanya untuk menampung dan mengalirkan limpasan air hujan, tetapi juga untuk menampung dan mengalirkan air limbah domestik, dan menyediakan air bagi kebutuhan rumah tangga. Hasil pemantauan BLH Kota Pontianak pada tahun 2011 menunjukkan kualitas air Sungai Jawi sebagaimana yang diperlihatkan pada Tabel 1 (BLH Kota Pontianak, 2011). 
Tabel 1: Pemantauan Kualitas Air Pemukaan Sungai Jawi

\begin{tabular}{|c|c|c|c|c|}
\hline \multirow{2}{*}{ Parameter } & \multirow{2}{*}{ Satuan } & \multirow{2}{*}{ Baku mutu $^{*}$} & \multicolumn{2}{|c|}{ Hasil } \\
\cline { 4 - 5 } & & & I & II \\
\hline Temperatur & ${ }^{\circ} \mathrm{C}$ & Deviasi 3** & 29 & 28,1 \\
\hline DO & $\mathrm{mg} / \mathrm{l}$ & M in. 4 & 9,55 & 8,21 \\
\hline BOD & $\mathrm{mg} / \mathrm{l}$ & Maks. 3 & 13,2 & 14,2 \\
\hline
\end{tabular}

Sumber : Hasi Uji Laboratorium BLH Kota Pontianak, Tahun 2011

Keterangan: *Baku Mutu berdasarkan PP No. 82 Tahun 2001 (Kelas II), ** Deviasi 3 menyatakan bahwa temperatur air berada diambang baku mutu jika $\pm 3^{\circ} \mathrm{C}$ dari temperatur dalam keadaan alamiahnya

Berdasarkan Tabel 1 dapat dilihat bahwa nilai parameter BOD di dua titik sampel telah melebihi baku mutu berdasarkan PP No. 82 Tahun 2001 tentang Pengelolaan Kualitas Air dan Pengendalian Pencemaran Air untuk perairan kelas II yaitu maksimal sebesar $3 \mathrm{mg} / \mathrm{l}$. Hal ini menandakan tingginya bahan organik yang masuk ke dalam Sungai Jawi sehingga menurunkan kemampuan swa purifikasi sungai. Untuk itu perlu kiranya dilakukan kajian mengenai proses swa purifikasi Sungai Jawi sehingga dapat direncanakan upaya yang dapat mempercepat terjadinya proses swa purifikasi agar tingkat pencemaran air di dalam saluran dapat berkurang.

\section{DASAR TEORI}

James (1984) di dalam Rachimi (2003) mengemukakan bahwa pada kondisi umum saluran bukan hanya untuk menampung limpasan air permukaan tetapi juga menjadi tempat pembuangan air limbah domestik dan industri. Sepanjang beban buangan tidak melebihi kapasitas saluran, proses yang terjadi di perairan tersebut berlangsung secara aerobik. Hal ini disebabkan karena adanya proses swa purifikasi di dalam saluran. Swa purifikasi merupakan suatu proses alami dimana suatu saluran mempertahankan kondisi asalnya melawan bahan-bahan asing yang masuk ke dalam saluran (Heryna, 2008). M ekanisme swa purifikasi dari sistem air di alam yaitu terdiri atas proses fisika, kimia dan biologi. Karakteristik hidraulik, seperti volume, debit dan aliran turbulen, karakteristik fisik pada dasar dan tampungan material, variasi intensitas sinar matahari dan suhu, serta sifat kimia air, semua merupakan variabel sistem yang mempunyai pengaruh pada proses purifikasi secara alami. Dalam proses swa purifikasi sungai, dilibatkan juga mikroorganisme seperti bakteri, protozoa, alga dan organisme tingkat rendah lainnya yang berperan dalam proses penguraian bahan organik.

\section{METODE PENELITIAN}

Perencanaan ini berlokasi di Sungai Jawi yang berada dalam wilayah administrasi Kota Pontianak. Muara Sungai Jawi berada di Sungai Kapuas dan hulu sungai berada di Parit Haruna. Pengamatan dilakukan saat pasang dan surut pada musim kemarau, bulan Mei 2012. Perbaikan kemampuan swa purifikasi ditujukan untuk meningkatkan konsentrasi Oksigen dengan cara merekayasa penampang dan penambahan alat tertentu.

Untuk menentukan rekayasa penampang dan penambahan alat agar konsentrasi Oksigen meningkat, terlebih dahulu dilakukan analisis untuk mengetahui dan menghitung kondisi saluran drainase eksisting serta kemampuan swa purifikasi saluran khususnya ditinjau dari Oksigen terlarut eksisting pada kondisi surut. Kemudian mengevaluasi kemampuan Sungai Jawi pada kondisi eksisting apakah mampu melakukan proses swa purifikasi secara optimal untuk selanjutnya dilakukan perencanaan. Adapun proses analisis yang akan dilakukan adalah sebagai berikut:

1. Menetapkan Oksigen terlarut (DO) target untuk Sungai Jawi berdasarkan PP No. 82 Tahun 2001 tentang Pengelolaan Kualitas Air dan Pengendalian Pencemaran Air untuk perairan kelas II dan berdasarkan konsentrasi Oksigen terlarut minimal bagi biota pengguna Oksigen yaitu sebesar 4 $\mathrm{mg} / \mathrm{l}$.

2. Menghitung koefisien reaerasi $(\mathrm{Kr})$ dan koefisien deOksigenasi. Rumus yang digunakan adalah (O'Connor dan Dobbins (1958) dan Hydroscience (1971)): 


\section{Koefisien Reaerasi (Kr)}

$$
\begin{aligned}
& K_{r}\left(20^{\circ} \mathrm{C}\right)=3,9 \frac{V^{0,5}}{H^{1,5}} \\
& K r=K r_{20^{\circ}} \times 1,0238^{\left(T-20^{\circ}\right)} \\
& \text { Koefisien DeOksigenasi (Kd) } \\
& K_{d}\left(20^{\circ} \mathrm{C}\right)=0,3\left(\frac{H}{8}\right)^{-0,434} \\
& K_{d}=K d_{20} \times 1,048^{(T-20)}
\end{aligned}
$$

3. Menghitung penampang saluran hasil rekayasa berdasarkan perolehan nilai koefisien reaerasi (Kr) dengan menggunakan rumus penampang terbaik yaitu persegi.

4. Menghitung defisit Oksigen yang terjadi setelah dilakukan rekayasa saluran. Rumus yang digunakan adalah:

$$
D=\frac{k_{2} L_{0}}{k_{2}-k_{1}}\left(e^{-k_{1} t}-e^{-k_{2} t}\right)+D_{0} e^{-k_{2} t}
$$

5. Melakukan analisis perbaikan konsentrasi Oksigen terlarut dengan menggunakan aerator.

a. Menghitung kinerja aerator yang diharapkan. Rumus yang digunakan adalah (Rich, 2001):

$$
N=N o \frac{\rho c^{*}-c}{9,17} \alpha \gamma
$$

b. Menghitung kecepatan pemanfaatan Oksigen $\left(R_{02}\right)$. Rumus yang digunakan adalah (Rich, 2001):

$$
R_{O 2}=6,13 \times 10^{-5} Q x S_{0}
$$

C. Menghitung daya level aerator (P). Rumus yang digunakan adalah (Rich, 2001):

$$
P=10^{3} \times \frac{R o_{2}}{N \times V}
$$

\section{HASIL DAN PEMBAHASAN}

A. Analisis Saluran Sungai Jawi Eksisting

Kondisi eksisting Sungai Jawi merupakan saluran dengan penampang persegi dengan dinding saluran dibagian hulu berupa tanah dan dibagian hilir berupa turap beton. Berikut penyajian data eksisting Sungai Jawi berdasarkan pengamatan di lapangan pada Tabel 2.

Tabel 2: Kondisi Dimensi Saluran Eksisting Sungai Jawi

\begin{tabular}{|c|l|c|c|c|c|c|c|}
\hline No. & \multicolumn{1}{|c|}{ Titik Sampel } & $\begin{array}{c}\mathbf{y} \\
\mathbf{( m )}\end{array}$ & $\begin{array}{c}\mathbf{b} \\
\mathbf{( m )}\end{array}$ & $\begin{array}{c}\mathbf{A} \\
\left(\mathbf{m}^{\mathbf{2}} \mathbf{)}\right.\end{array}$ & $\begin{array}{c}\mathbf{P} \\
\mathbf{( m )}\end{array}$ & $\begin{array}{c}\mathbf{R} \\
\mathbf{( m )}\end{array}$ & $\begin{array}{c}\mathbf{v} \\
(\mathbf{m} / \mathbf{s})\end{array}$ \\
\hline 1 & Parit Haruna & 0,63 & 15,68 & 9,95 & 16,95 & 0,59 & 0,10 \\
\hline 2 & Ampera & 0,87 & 16,42 & 14,32 & 18,16 & 0,79 & 0,10 \\
\hline 3 & As Salam & 0,71 & 18,56 & 13,14 & 19,98 & 0,66 & 0,30 \\
\hline 4 & Pal 5 & 0,74 & 17,97 & 13,30 & 19,45 & 0,68 & 0,10 \\
\hline 5 & Pal 3 & 0,62 & 17,87 & 11,16 & 19,12 & 0,58 & 0,30 \\
\hline 6 & Swignyo & 0,87 & 13,65 & 11,82 & 15,38 & 0,77 & 0,30 \\
\hline 7 & Pancasila & 0,82 & 12,43 & 10,16 & 14,06 & 0,72 & 0,30 \\
\hline 8 & Bukit Barisan & 0,78 & 13,50 & 10,54 & 15,06 & 0,70 & 0,30 \\
\hline 9 & Pasar Dahlia & 0,69 & 12,50 & 8,63 & 13,88 & 0,62 & 0,30 \\
\hline 10 & Penjara & 0,81 & 15,10 & 12,27 & 16,73 & 0,73 & 0,30 \\
\hline 11 & Merdeka & 1,06 & 15,40 & 16,32 & 17,52 & 0,93 & 0,30 \\
\hline 12 & Gertak I (Sui Jawi) & 1,08 & 15,90 & 17,19 & 18,06 & 0,95 & 0,30 \\
\hline & Rata-rata & $\mathbf{0 , 8 1}$ & $\mathbf{1 5 , 4 2}$ & $\mathbf{1 2 , 4 0}$ & $\mathbf{1 7 , 0 3}$ & $\mathbf{0 , 7 3}$ & $\mathbf{0 , 2 5}$ \\
\hline
\end{tabular}

\section{B. Analisis Kemampuan Swa Purifikasi Saluran Sungai Jawi}

Berbagai aktivitas manusia di sepanjang Sungai Jawi mengakibatkan tingginya buangan bahan organik ke dalam saluran sehingga mempengaruhi kualitas air, yang ditunjukkan oleh nilai Oksigen terlarut yang rendah. Tabel 3 (Hasil Uji Laboratorium Kesehatan Pontianak, 2012) berikut ini adalah 
data hasil uji kualitas air saluran Sungai jawi berdasarkan hasil pengukuran pada saat pasang dan surut.

Tabel 3: Data Kualitas Air Saluran Sungai Jawi

\begin{tabular}{|c|c|c|c|c|c|}
\hline \multirow{3}{*}{ No. } & \multirow{3}{*}{ Titik Sampel } & \multicolumn{4}{|c|}{ Hasil Uji Laboratorium } \\
\hline & & \multicolumn{2}{|c|}{ Pasang } & \multicolumn{2}{|c|}{ Surut } \\
\hline & & $\begin{array}{c}\text { DO } \\
\text { (mg/L) }\end{array}$ & $\begin{array}{c}\text { BOD } \\
\text { (mg/L) }\end{array}$ & $\begin{array}{c}\text { DO } \\
\text { (mg/L) }\end{array}$ & $\begin{array}{c}\text { BOD } \\
\text { (mg/L) }\end{array}$ \\
\hline 1 & Parit Haruna & 1,0 & 12,0 & 1,4 & 6,0 \\
\hline 2 & Ampera & 0,9 & 19,0 & 1,1 & 15,0 \\
\hline 3 & As Salam & 3,2 & 12,0 & 2,6 & 19,0 \\
\hline 4 & Pal 5 & 1,8 & 15,0 & 2,0 & 16,0 \\
\hline 5 & Pal 3 & 1,4 & 14,0 & 1,8 & 6,0 \\
\hline 6 & Swignyo & 1,4 & 6,0 & 0,9 & 6,0 \\
\hline 7 & Pancasila & 1,4 & 6,0 & 1,3 & 17,0 \\
\hline 8 & Bukit Barisan & 1,8 & 14,0 & 1,2 & 15,0 \\
\hline 9 & Pasar Dahlia & 3,4 & 5,0 & 5,1 & 13,0 \\
\hline 10 & Penjara & 2,9 & 5,0 & 0,8 & 15,0 \\
\hline 11 & Merdeka & 3,5 & 4,7 & 1,2 & 15,0 \\
\hline 12 & Gertak I (Sui Jawi) & 4,1 & 6,0 & 1,0 & 13,0 \\
\hline
\end{tabular}

Sumber: Hasil Uji Laboratorium Kesehatan Pontianak, 2012

Kterengan: *Baku mutu kualitas air berdasarkan PP No. 82 tentang Pengelolaan Kualitas Air dan Pengendalian Pencemaran Air (Kelas II), untuk BOD maks. 3 mg/I dan DO min.4 mg/l

Berdasarkan data pada Tabel 3, selanjutnya digambarkan grafik konsentrasi Oksigen terlarut di dalam Sungai Jawi untuk kedua kondisi seperti yang ditunjukkan pada Gambar 1 dan Gambar 2 berikut ini.

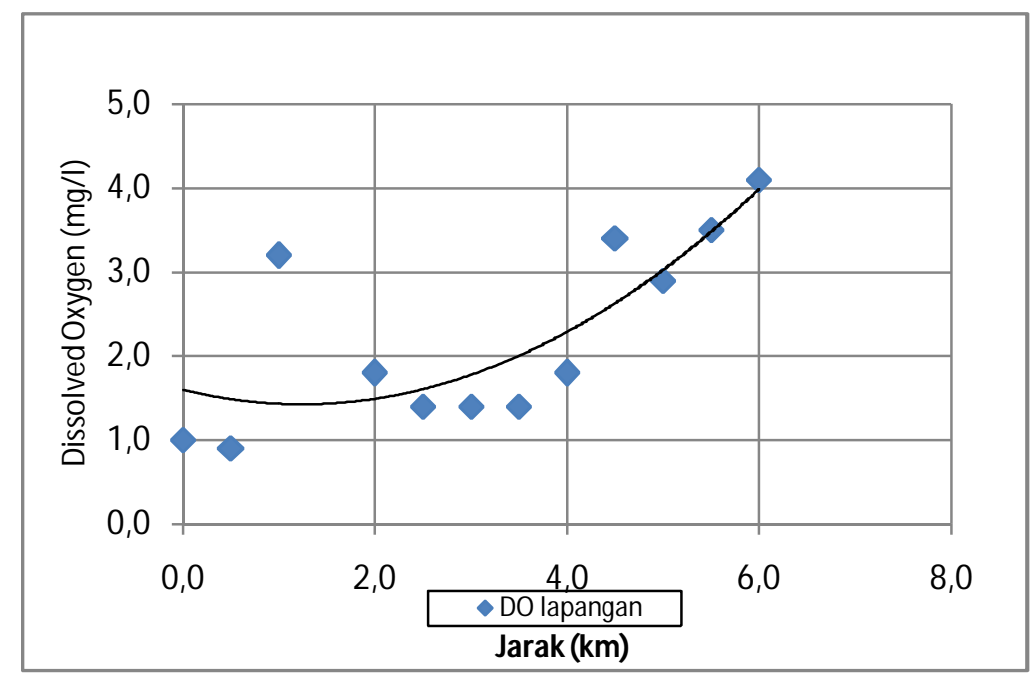

Gambar 1: Grafik konsentrasi Oksigen terlarut pada saat pasang 


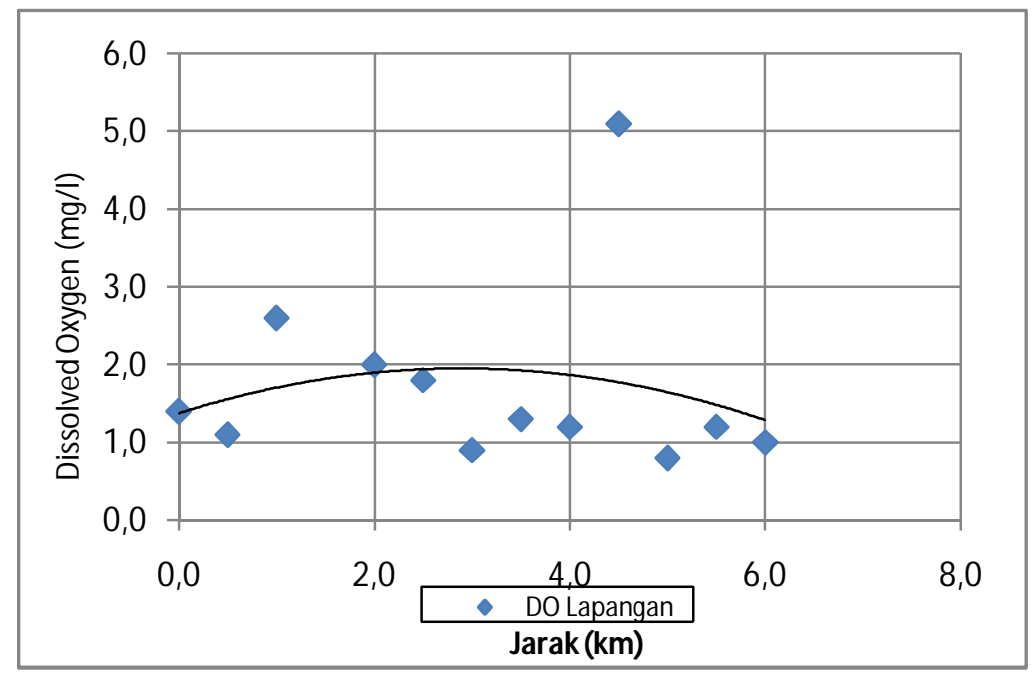

Gambar 2: Grafik konsentrasi Oksigen terlarut pada saat surut

Berdasarkan Gambar 1 dapat dilihat ketika kondisi pasang, konsentrasi Oksigen terlarut bertambah ke arah muara karena adanya pergolakan air akibat arus pasang dan penambahan volume air sehingga terjadi proses pengenceran dan konsentrasi bahan organik di dalam badan air. Namun, berdasarkan Gambar 2, ketika kondisi surut menunjukkan penurunan DO ke arah muara Sungai Jawi yang diakibatkan oleh banyaknya limbah yang masuk ke saluran, sedimentasi di dasar saluran yang mengakibatkan pendangkalan, serta sampah-sampah sehingga kualitas air menurun akibat berkurangnya difusi Oksigen, karena digunakan oleh bakteri aerobik dalam proses pemecahan bahan organik yang berasal dari limbah domestik. Hal ini ditunjukkan pula oleh hasil uji BOD ketika surut, dimana BOD di Sungai Jawi melebihi baku mutu menurut PP No. 82 Tahun 2001 tentang Pengelolaan Kualitas Air dan Pengendalian Pencemaran Air (Kelas II) yaitu maksimal 3 mg/l.

Berdasarkan data kualitas air Sungai Jawi pada Tabel 3, dilakukan analisis mengenai koefisien reaerasi $(\mathrm{Kr})$, koefisien deOksigenasi $(\mathrm{Kd})$, dan defisit Oksigen (D) saluran Sungai Jawi. Berikut ini Tabel 4, hasil analisis perhitungan Kr, Kd, dan defisit Oksigen eksisting saluran Sungai Jawi.

Tabel 4: Koefisien DeOksigenasi (Kd), Koefisien Reaerasi (Kr) Eksisting, dan Defisit Oksigen (D) Pada Saat Pasang dan Surut

\begin{tabular}{|c|l|c|c|c|c|c|c|c|c|}
\hline \multirow{2}{*}{ No. } & \multirow{2}{*}{$\begin{array}{c}\text { Titik } \\
\text { Sampel }\end{array}$} & \multicolumn{2}{c|}{$\begin{array}{c}\text { Do lapangan } \\
\text { (mg/l) }\end{array}$} & \multicolumn{2}{c|}{ Kd } & \multicolumn{2}{c|}{ Kr } & \multicolumn{2}{c|}{$\begin{array}{c}\text { D } \\
\text { (mg/l) }\end{array}$} \\
\cline { 3 - 12 } & & Pasang & Surut & Pasang & Surut & Pasang & Surut & Pasang & Surut \\
\hline 1 & Parit Haruna & 1,0 & 1,4 & 0,83 & 1,31 & 0,78 & 3,67 & 7,11 & 6,43 \\
\hline 2 & Ampera & 0,9 & 1,1 & 0,81 & 1,14 & 1,56 & 0,45 & 7,17 & 7,50 \\
\hline 3 & As Salam & 3,2 & 2,6 & 0,92 & 1,31 & 1,11 & 0,67 & 4,94 & 5,50 \\
\hline 4 & Pal 5 & 1,8 & 2,0 & 0,78 & 1,29 & 1,08 & 1,67 & 6,67 & 6,70 \\
\hline 5 & Pal 3 & 1,4 & 1,8 & 0,86 & 1,32 & 1,00 & 1,33 & 6,86 & 6,03 \\
\hline 6 & Swignyo & 1,4 & 0,9 & 0,81 & 1,20 & 0,77 & 0,22 & 6,55 & 6,90 \\
\hline 7 & Pancasila & 1,4 & 1,3 & 0,88 & 0,85 & 1,13 & 1,17 & 6,31 & 7,71 \\
\hline 8 & Bukit Barisan & 1,8 & 1,2 & 0,73 & 1,26 & 0,88 & 1,60 & 6,40 & 6,65 \\
\hline 9 & Pasar Dahlia & 3,4 & 5,1 & 0,76 & 1,15 & 1,13 & 0,86 & 4,54 & 3,24 \\
\hline 10 & Penjara & 2,9 & 0,8 & 0,72 & 1,07 & 0,87 & 0,25 & 5,05 & 7,58 \\
\hline 11 & Merdeka & 3,5 & 1,2 & 0,65 & 0,96 & 1,38 & 0,50 & 4,56 & 6,9 \\
\hline 12 & Gertak I (Sui Jawi) & 4,1 & 1,0 & 0,64 & 0,95 & 2,75 & 2,75 & 3,62 & 7,1 \\
\hline
\end{tabular}

Dari Tabel 4 di atas, dapat dilihat bahwa nilai defisit DO ketika surut lebih besar dibandingkan ketika pasang. Meskipun proses perpindahan Oksigen yang berasal dari udara ke badan air (Kr) lebih besar ketika surut dan telah melebihi standar berdasarkan KEPM EN LH No. 110 Tahun 2003 untuk 
kolam kecil dan perairan yaitu sebesar $0,10-0,23$, namun tingginya BOD serta tingginya nilai $\mathrm{Kd}$ menunjukkan bahwa tingkat penggunaan DO oleh mikroorganisme di Sungai Jawi juga cukup besar dibandingkan dengan kondisi pasang. Hal ini ikut mempengaruhi tingginya defisit Oksigen di Sungai Jawi. Meskipun nilai Kr Sungai Jawi sudah cukup tinggi, namun kemungkinan terjadinya penurunan nilai DO akibat banyaknya limbah domestik yang terus masuk tanpa proses pengolahan terlebih dahulu ataupun pengenceran jika terjadi peningkatan laju penggunaan DO.

Dari hasil analisis di atas, akan dilakukan cara untuk meningkatkan difusi Oksigen terlarut khususnya pada saat air surut. Hal tersebut merupakan salah satu upaya untuk menjaga kemampuan swa purifikasi Sungai Jawi. Cara untuk memperbaiki konsentrasi Oksigen di dalam Sungai Jawi pada penelitian ini, pertama dengan menetapkan DO target sebesar $4 \mathrm{mg} / \mathrm{l}$. DO target ini disesuaikan pula dengan standar baku mutu kualitas air Sungai Jawi yang digunakan sebagai acuan yaitu PP. No 82 Tahun 2001 tentang Pengelolaan Kualitas Air dan Pengendalian Pencemaran Air untuk Perairan Kelas II yaitu minimal 4 mg/l. Tabel 5 menunjukkan perbedaan antara DO lapangan dan DO target untuk saluran Sungai Jawi.

Tabel 5: Penetapan DO Target Berdasarkan Pada Hasil Uji Laboratorium DO Lapangan Pada Saat Kondisi Air Surut

\begin{tabular}{|c|l|c|c|}
\hline No. & \multicolumn{1}{|c|}{$\begin{array}{c}\text { Titik } \\
\text { Sampel }\end{array}$} & $\begin{array}{c}\text { Do Lapangan } \\
(\mathbf{m g} / \mathbf{l})\end{array}$ & $\begin{array}{c}\text { Do Target } \\
(\mathbf{m g} / \mathbf{l})\end{array}$ \\
\hline 1 & Parit Haruna & 1,4 & 4,0 \\
\hline 2 & Ampera & 1,1 & 4,0 \\
\hline 3 & As Salam & 2,6 & 4,0 \\
\hline 4 & Pal 5 & 2,0 & 4,0 \\
\hline 5 & Pal 3 & 1,8 & 4,0 \\
\hline 6 & Swignyo & 0,9 & 4,0 \\
\hline 7 & Pancasila & 1,3 & 4,0 \\
\hline 8 & Bukit Barisan & 1,2 & 4,0 \\
\hline 9 & Pasar Dahlia & 5,1 & 5,1 \\
\hline 10 & Penjara & 0,8 & 4,0 \\
\hline 11 & Merdeka & 1,2 & 4,0 \\
\hline 12 & Gertak I (Sui Jawi) & 1,0 & 4,0 \\
\hline
\end{tabular}

Dengan menetapkan DO target sebesar $4 \mathrm{mg} / \mathrm{l}$ pada saluran Sungai Jawi, maka diharapkan difusi Oksigen terlarut di dalam air dapat meningkat sehingga konsentrasi Oksigen terlarut di dalam air meningkat pula. Namun, pada titik 9 tidak dilakukan penetapan DO target. Hal ini dikarenakan hasil uji kadar DO di dalam badan air pada titik 9 sebesar 5,1 mg/l telah melebihi DO target yang ditetapkan, hal ini mungkin terjadi dikarenakan pada saat proses pengambilan sampel air di lapangan dilakukan pada posisi di depan tiang jembatan, sehingga terlebih dahulu terjadi difusi Oksigen akibat adanya turbulensi yang diakibatkan tumbukan air terhadap tiang jembatan. Diharapkan dengan adanya rekayasa ini konsentrasi DO pada titik 9 tidak berubah. Selanjutnya akan dilakukan rekayasa atau penambahan alat di saluran Sungai Jawi.

\section{Analisis Koefisien DeOksigenasi (Kd) dan Koefisien Reaerasi (Kr)}

Dari hasil analisis mengenai kualitas air dengan parameter Oksigen terlarut yang telah ditargetkan, maka diperoleh nilai koefisien reaerasi ( $\mathrm{Kr}$ ) dan koefisien deOksigenasi (Kd) untuk 12 titik pengambilan sampel air, seperti pada Tabel 6 berikut ini. 
Tabel 6: Hasil Analisis Kd, Kr, dan Defisit Oksigen Rencana pada Kondisi Surut di Saluran Sungai Jawi

\begin{tabular}{|c|c|c|c|c|c|c|c|c|c|c|c|}
\hline No & Titik & $\begin{array}{c}\text { DO } \\
\text { Lapangan }\end{array}$ & $\begin{array}{c}\text { DO } \\
\text { Target }\end{array}$ & $\begin{array}{c}\text { Kecepatan* } \\
\text { (v) }\end{array}$ & $\begin{array}{c}\text { Kedalaman** } \\
\text { (H) }\end{array}$ & $\begin{array}{c}\text { Temperatur } \\
\text { (T) }\end{array}$ & $\begin{array}{c}\mathrm{Kd} \\
\left(20^{\circ} \mathrm{C}\right)\end{array}$ & Kd & $\begin{array}{c}\mathrm{Kr} \\
\left(20^{\circ} \mathrm{C}\right)\end{array}$ & $\mathbf{K r}$ & $\begin{array}{c}D \\
(m g / l)\end{array}$ \\
\hline 1 & Parit Haruna & 1,40 & 4,00 & 0,90 & 1,02 & 28,00 & 0,73 & 1,07 & 3,59 & 4,34 & 3,83 \\
\hline 2 & Ampera & 1,10 & 4,00 & 0,90 & 1,60 & 28,00 & 0,60 & 0,88 & 1,83 & 2,21 & 3,86 \\
\hline 3 & As Salam & 2,60 & 4,00 & 0,90 & 1,04 & 29,00 & 0,73 & 1,11 & 3,49 & 4,31 & 3,72 \\
\hline 4 & Pal 5 & 2,00 & 4,00 & 0,90 & 1,30 & 29,00 & 0,66 & 1,01 & 2,50 & 3,08 & 3,75 \\
\hline 5 & Pal 3 & 1,80 & 4,00 & 0,90 & 1,04 & 28,00 & 0,73 & 1,06 & 3,49 & 4,21 & 3,77 \\
\hline 6 & Swignyo & 0,90 & 4,00 & 0,90 & 1,11 & 29,00 & 0,71 & 1,08 & 3,16 & 3,91 & 3,64 \\
\hline 7 & Pancasila & 1,30 & 4,00 & 0,90 & 1,16 & 21,00 & 0,69 & 0,73 & 2,96 & 3,03 & 4,89 \\
\hline 8 & Bukit Barisan & 1,20 & 4,00 & 0,90 & 1,20 & 29,00 & 0,68 & 1,04 & 2,81 & 3,48 & 3,71 \\
\hline 9 & Pasar Dahlia & 5,10 & 5,10 & 0,90 & 1,02 & 26,00 & 0,73 & 0,97 & 3,59 & 4,14 & 3,01 \\
\hline 10 & Penjara & 0,80 & 4,00 & 0,90 & 1,25 & 26,00 & 0,67 & 0,89 & 2,65 & 3,05 & 4,11 \\
\hline 12 & Gertak I (Sui Jawi) & 1,00 & 4,00 & 0,90 & 1,57 & 26,00 & 0,61 & 0,81 & 1,88 & 2,17 & 4,12 \\
\hline
\end{tabular}

Sumber: Hasil Analisis, 2012

Keterangan : *merupakan $\mathrm{V}_{\text {izin }}$ saluran drainase kota dengan dinding dari batu atau beton minimum $=0,9 \mathrm{~m} / \mathrm{s}$, **kedalaman maksimum eksisting per titik sampel

Dari Tabel 6 diatas untuk menaikkan nilai $\mathrm{Kr}$ dapat dilakukan dengan cara mengubah dinding saluran menjadi susunan batu atau beton. Pada perencanaan ini penggunaan kedalaman maksimum per titik sampel dikarenakan apabila menggunakan kedalaman lebih dari kedalaman maksimum dikhawatirkan tercampurnya air tanah dengan air permukaan sehingga mempengaruhi kualitas air Sungai Jawi itu sendiri, dimana kualitas air tanah yang ada di lokasi pengambilan sampel tidak diketahui. Sedangkan penggunaan kecepatan izin minimum diasumsikan berdasarkan Hardjosuprapto (1996), untuk saluran drainase kota dengan dinding dari batu atau beton kecepatan aliran di dalam saluran pada saat mengalirkan debit puncak antara 0,9 - $3 \mathrm{~m} / \mathrm{s}$. Diharapkan dengan kecepatan tersebut sudah dapat mengakibatkan turbulensi di dalam saluran Sungai Jawi. Berikut ini, Tabel 7 hasil perbandingan antara defisit Oksigen eksisting dan defisit Oksigen rekayasa.

Tabel 7: Perbandingan Antara Defisit Oksigen Eksisting dan Defisit Oksigen Rekayasa

\begin{tabular}{|c|l|c|c|c|}
\hline No. & Titik Sampel & $\begin{array}{c}\text { Defisit Oksigen } \\
\text { Lapangan } \\
\text { (mg/l) }\end{array}$ & $\begin{array}{c}\text { Defisit Oksigen } \\
\text { Rekayasa } \\
\text { (mg/l) }\end{array}$ & $\begin{array}{c}\text { Persentase } \\
\text { Penurunan D } \\
\text { (\%) }\end{array}$ \\
\hline 1 & Parit Haruna & 6,43 & 3,83 & 59,56 \\
\hline 2 & Ampera & 7,43 & 3,86 & 52,03 \\
\hline 3 & As Salam & 5,47 & 3,74 & 68,32 \\
\hline 4 & Pal 5 & 6,76 & 3,71 & 54,88 \\
\hline 5 & Pal 3 & 6,01 & 3,79 & 62,96 \\
\hline 6 & Swignyo & 6,90 & 3,64 & 52,81 \\
\hline 7 & Pancasila & 7,71 & 4,89 & 63,44 \\
\hline 8 & Bukit Barisan & 6,68 & 3,69 & 55,29 \\
\hline 9 & Pasar Dahlia & 3,24 & 3,03 & 93,56 \\
\hline 10 & Penjara & 7,60 & 4,10 & 53,90 \\
\hline 11 & Merdeka & 7,14 & 4,13 & 57,86 \\
\hline 12 & Gertak I (Sui Jawi) & 7,03 & 4,08 & 58,06 \\
\hline Rata-rata & $\mathbf{6 , 5 3}$ & $\mathbf{3 , 8 8}$ & $\mathbf{6 1 , 1 3}$ \\
\hline
\end{tabular}

Sumber: Hasil Analisis, 2012

Berdasarkan Tabel 7 terjadi penurunan defisit Oksigen pada hasil rekayasa, dari defisit Oksigen eksisting rata-rata sebesar $6,53 \mathrm{mg} / \mathrm{l}$ menjadi $3,88 \mathrm{mg} / \mathrm{l}$ pada defisit Oksigen rekayasa, jika di persentasikan penurunan defisit Oksigen rata-rata mencapai $61,13 \%$. Hal ini menunjukkan bahwa terjadi perbaikan konsentrasi Oksigen Sungai Jawi akibat adanya proses rekayasa pada dinding 
saluran. Untuk meningkatkan nilai Kr maka diperoleh hasil perkiraan penampang saluran yang sesuai agar terjadinya reaerasi secara optimal seperti pada Tabel 8 berikut ini.

Tabel 8: Hasil Analisis Penampang Saluran Sungai Jawi Berdasarkan Perolehan Nilai Koefisien Reaerasi

\begin{tabular}{|c|l|c|c|c|c|c|c|c|c|}
\hline No. & \multicolumn{1}{|c|}{ Titik Sampel } & $\begin{array}{c}\mathbf{v} \\
\mathbf{( m / \mathbf { s }}\end{array}$ & $\begin{array}{c}\mathbf{y} \\
\mathbf{( m )}\end{array}$ & $\begin{array}{c}\mathbf{b} \\
\mathbf{( m )}\end{array}$ & $\begin{array}{c}\mathbf{A} \\
\left(\mathbf{m}^{\mathbf{2}} \mathbf{)}\right.\end{array}$ & $\begin{array}{c}\mathbf{P} \\
\mathbf{( m )}\end{array}$ & $\begin{array}{c}\mathbf{R} \\
(\mathbf{m})\end{array}$ & $\mathbf{n}$ & $\mathbf{s}$ \\
\hline 1 & Parit Haruna & 0,90 & 1,02 & 15,68 & 15,99 & 17,72 & 0,90 & 0,012 & 0,0002 \\
\hline 2 & Ampera & 0,90 & 1,60 & 16,42 & 26,27 & 19,62 & 1,34 & 0,012 & 0,0002 \\
\hline 3 & As Salam & 0,90 & 1,04 & 18,56 & 19,30 & 20,64 & 0,94 & 0,012 & 0,0002 \\
\hline 4 & Pal 5 & 0,90 & 1,30 & 17,97 & 23,36 & 20,57 & 1,14 & 0,012 & 0,0002 \\
\hline 5 & Pal 3 & 0,90 & 1,04 & 17,87 & 18,58 & 19,95 & 0,93 & 0,012 & 0,0002 \\
\hline 6 & Swignyo & 0,90 & 1,11 & 13,65 & 15,15 & 15,87 & 0,95 & 0,012 & 0,0002 \\
\hline 7 & Pancasila & 0,90 & 1,16 & 12,43 & 14,42 & 14,75 & 0,98 & 0,012 & 0,0002 \\
\hline 8 & Bukit Barisan & 0,90 & 1,20 & 13,50 & 16,20 & 15,90 & 1,02 & 0,012 & 0,0002 \\
\hline 9 & Pasar Dahlia & 0,90 & 1,02 & 12,50 & 12,75 & 14,54 & 0,88 & 0,012 & 0,0002 \\
\hline 10 & Penjara & 0,90 & 1,25 & 15,10 & 18,88 & 17,60 & 1,07 & 0,012 & 0,0002 \\
\hline 11 & Merdeka & 0,90 & 1,80 & 15,40 & 27,72 & 19,00 & 1,46 & 0,012 & 0,0001 \\
\hline 12 & Gertak I (Sui Jawi) & 0,90 & 1,57 & 15,90 & 24,96 & 19,04 & 1,31 & 0,012 & 0,0001 \\
\hline
\end{tabular}

Dengan mempertimbangkan kondisi di lapangan diantaranya kapasitas debit dari limpasan permukaan, maka lebar saluran yang digunakan dalam perencanaan ini adalah lebar saluran eksisiting. Sehingga, analisis luas penampang $(A)$, keliling basah (P), dan jari-jari hidrolis (R) dapat dicari berdasarkan bentuk penampang melintang terbaik yaitu berbentuk segi empat. berdasarkan analisis pada Tabel 8, diperoleh bentuk penampang saluran Sungai Jawi seperti pada Gambar $\mathbf{3}$ berikut ini.

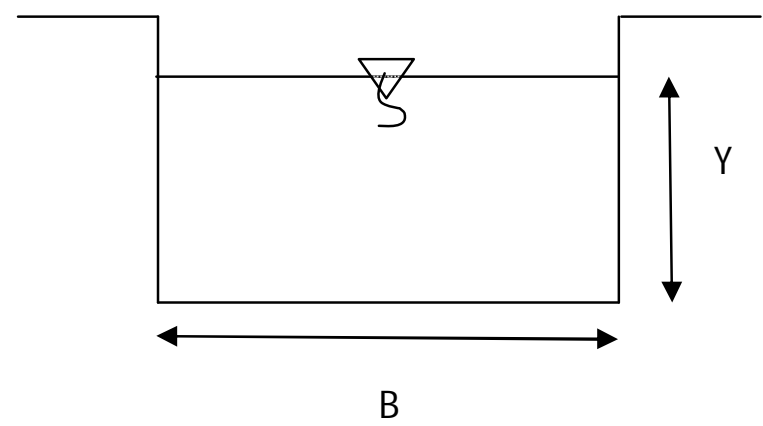

Gambar 3: Perencanaan bentuk penampang saluran Sungai Jawi

Berdasarkan Tabel 8, untuk mencapai kecepatan izin minimum sebesar 0,9 m/s, maka diperlukan kemiringan saluran pada perencanaan ini rata-rata sebesar 0,0002. Menurut hasil analisis yang pernah dilakukan oleh PT. Bayu Pratama Khatulistiwa tahun 2010 terhadap Sungai Jawi, kemiringan saluran Sungai Jawi adalah 0,0002. Hal ini menunjukkan bahwa kemiringan saluran eksisting Sungai Jawi dapat mengalirkan kecepatan air sebesar 0,9 m/s. Namun, berdasarkan pengukuran di lapangan, kecepatan aliran Sungai Jawi pada penelitian ini hanya berkisar antara 0,1$0,3 \mathrm{~m} / \mathrm{s}$, sehingga konsentrasi Oksigen akan sulit untuk diperbaiki. Oleh sebab itu, dipilih cara alternatif lain yang dapat memperbaiki konsentrasi Oksigen terlarut di dalam Sungai Jawi yaitu dengan penambahan aerator.

\section{Perbaikan Konsentrasi Oksigen Dengan M enggunakan Aerator}

Selain melakukan rekayasa terhadap dinding saluran Sungai Jawi, alternatif lain yang dapat dilakukan untuk meningkatkan konsentrasi Oksigen di Sungai Jawi agar kemampuan swa purifikasi Sungai Jawi meningkat yaitu dengan melakukan transfer Oksigen menggunakan aerator. Aerator yang digunakan yaitu aerator permukaan seperti yang ditujukan pada Gambar $\mathbf{4}$ berikut ini. 


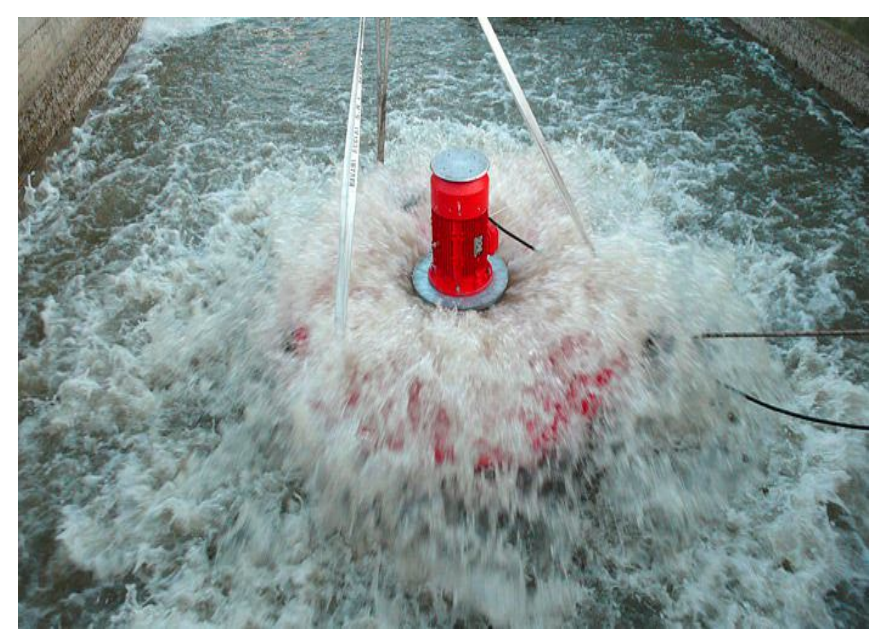

Gambar 4: Aerator permukaan

Aerator permukaan dipilih berdasarkan pertimbangan antara lain sebagai berikut:

1. Aerator dapat meningkatkan kandungan Oksigen di dalam air sebesar $60-75 \%$.

2. Kecepatan transfer Oksigen lebih optimum.

3. Lebih ekonomis (murah).

4. Dapat memindahkan air yang teraerasi dengan cepat ke area sekelilingnya sehingga area yang belum teraerasi dapat teraerasi dengan segera.

5. Dengan adanya sirkulasi udara, maka dapat mendorong berbagai macam gas berbahaya untuk dilepaskan ke atmosfer.

Perencanaan aerator didahului dengen menentukan nilai kinerja aerator yang dinyatakan dalam $\mathrm{kg} \mathrm{O}_{2}$ yang dapat ditransfer per $\mathrm{kWh}\left(\mathrm{kgO}_{2} / \mathrm{jam}-\mathrm{hp}\right)$. Kinerja tersebut kemudian dihubungkan dengan performance yang diharapkan terjadi dalam kondisi aerator digunakan di lapangan. Dalam penetapan kapasitas aerator, diperlukan penentuan daya (power) yang diperlukan untuk melakukan proses aerasi sehingga injeksi Oksigen di dalam air dapat berlangsung. Berikut ini Tabel 9 penyajian hasil analisis level daya daya yang dibutuhkan aerator yang diletakkan di saluran Sungai Jawi.

Tabel 9: Kinerja Aerator yang Diharapkan pada Saat Kondisi Surut

\begin{tabular}{|c|c|c|c|c|c|}
\hline No. & Titik Sampel & $\begin{array}{c}\mathrm{N} \\
\left(\mathrm{kg} \mathrm{O}_{2} / \mathrm{kWH}\right)\end{array}$ & $\begin{array}{c}\text { Kecepatan } \\
\text { Utilitas } \mathrm{O}_{2} \\
\left(\mathrm{RO}_{2}\right) \\
(\mathrm{kg} / \mathrm{jam}) \\
\end{array}$ & $\begin{array}{l}\text { Level } \\
\text { Daya }\end{array}$ & $\begin{array}{c}\text { Jumlah } \\
\text { Aerator } \\
\text { (buah) }\end{array}$ \\
\hline 1 & Parit Haruna & 0,85 & 31,61 & 18,73 & 3,00 \\
\hline 2 & Ampera & 0,85 & 113,73 & 46,83 & 3,00 \\
\hline 3 & As Salam & 0,84 & 396,77 & 180,37 & 4,00 \\
\hline 4 & Pal 5 & 0,84 & 112,69 & 50,63 & 3,00 \\
\hline 5 & Pal 3 & 0,85 & 106,43 & 56,19 & 5,00 \\
\hline 6 & Swignyo & 0,84 & 112,69 & 56,96 & 2,00 \\
\hline 7 & Pancasila & 0,92 & 247,36 & 146,62 & 3,00 \\
\hline 8 & Bukit Barisan & 0,84 & 251,21 & 142,39 & 1,00 \\
\hline 9 & Pasar Dahlia & 0,64 & 178,15 & 162,44 & 1,00 \\
\hline 10 & Penjara & 0,87 & 292,47 & 137,27 & 1,00 \\
\hline 11 & Merdeka & 0,87 & 389,06 & 137,27 & 2,00 \\
\hline 12 & Gertak I (Sui Jawi) & 0,87 & 355,11 & 118,38 & 2,00 \\
\hline
\end{tabular}

Sumber: Hasil Analisis, 2012

**No : berdasarkan kinerja aerator buatan pabrik 1,2-2,4 kgO $/$ kWh (Duncan Mara, 1975) 
Berdasarkan Tabel 9 di atas maka dapat diketahui level daya aerator yang akan digunakan untuk saluran Sungai Jawi antara 18,73-180,37 (w/ $\left.\mathrm{m}^{3}\right)$. Dengan jumlah aerator sebanyak 30 buah yang diletakkan per 200 meter di sepanjang Sungai Jawi. Penempatan dengan jarak 200 meter dilakukan agar penambahan Oksigen terlarut dapat terjadi secara optimal sehingga penurunan Oksigen terlarut di dalam Sungai Jawi akibat penggunaan oleh mikroorganisme yang terus menerus mendegradasi limbah domestik yang masuk di sepanjang aliran dapat diminimalisir, akibatnya tidak terjadi defisit Oksigen yang berlebihan di dalam badan air, sehingga proses swa purifikasi dapat berjalan secara optimal.

\section{KESIM PULAN}

Dari perencanaan yang telah dilaksanakan maka dapat disimpulkan ;

1. Ketika kondisi saluran Sungai Jawi pasang, terjadi kenaikan konsentrasi Oksigen di dalam saluran. Namun, ketika saluran Sungai Jawi dalam kondisi surut, terjadi penurunan konsentrasi Oksigen di dalam saluran. Hal ini menunjukkan bahwa, pada saat kondisi air surut kemampuan swa purifikasi saluran Sungai Jawi belum terjadi secara optimal.

2. Kemampuan swa purifikasi ditinjau berdasarkan faktor koefisien reaerasi ( $\mathrm{Kr})$, yaitu dengan cara menaikkan nilai $\mathrm{Kr}$ sehingga difusi Oksigen di dalam air diharapkan terjadi secara maksimal sesuai dengan konsentrasi DO yang telah ditargetkan sebesar $4 \mathrm{mg} / \mathrm{l}$ dengan mengganti dinding saluran menjadi beton atau susunan batu. Selain itu, dilakukan pula injeksi Oksigen ke dalam air dengan penambahan aerator di saluran.

3. Penambahan aerator menjadi cara yang dipilih untuk memperbaiki konsentrasi Oksigen terlarut di badan air Sungai Jawi. Aerator yang dipilih yaitu aerator permukaan dengan level daya yang diperlukan berkisar antara 18,73 - 180,37 w/m³. Dengan jumlah aerator sebanyak 30 buah.

\section{Ucapan Terima Kasih}

Penulis mengucapkan terima kasih kepada kedua orang tua yang telah memberi dukungan secara moril maupun materil. Penulis juga mengucapkan terima kasih kepada Bapak Winardi Yususf, ST, M T dan Bapak Kiki Prio Utomo, ST, M. Sc selaku dosen pembimbing dalam perencanaan ini. Tidak lupa juga kepada teman-teman angkatan 2008 dan 2007 Fakultas Teknik UNTAN yang telah sangat berjasa membantu dalam pengerjaan skripsi ini.

\section{Referensi}

Davis, Mackenzie L and David A. Cornwell. 1991. Introduction to environmental engineering $2^{\text {nd }}$ edition - International edition. McGraw-Hill. Singapore.

Duncan, Mara. 1975. Pengolahan air Limbah di Daerah Iklim Panas (Sewage Treatment in Hot Climates) - Penterjemah : M ohajit. Bandung. Institut Teknologi Bandung.

Davis, Mackenzie $L$ and David A. Cornwell. 1991. Introduction to environmental engineering $2^{\text {nd }}$ edition - International edition. McGraw-Hill. Singapore.

Hardjosuprapto, M. Masduki. 1996. Desain Drainase Perkotaan Vol. 1. Bandung: ITB.

Heryna Oktaviania K. 2008. Pengaruh Kontraksi Penampang Saluran Terhadap Kualitas Fisik air Sungai, Studi Kasus : Sungai Sugutamu. Depok. Universitas Indonesia.

Linvil, G. Rich. 2001. Sistem Pengolahan Air Limbah Pemeliharaan Rendah, Mekanikal Sederhana (Low Maintenance, Mechanically Simple Wastewater Treatment Systems) - Penterjemah : Mohajit. Bandung. Institut Teknologi Bandung.

Rachimi. 2003. Beban Bahan Organik dan Kemampuan Self-Purification Sungai Jawi Di Pontianak. Bogor. Institut Pertanian Bogor. 